\title{
Sulfide Precipitation in Titanium-Added Steel with Residual Level of Copper (3) -Decrease of Copper Sulfide by Long-Time-Annealing in Ferrite Region-
}

\author{
Yasuhide Ishiguro $^{1, * 1}$, Takashi Murayama ${ }^{2, * 2}$, Takeshi Fujita ${ }^{3}$ and Kotaro Kuroda ${ }^{4}$ \\ ${ }^{1}$ Steel Research Laboratory, JFE Steel Corporation, 1-1 Kawasaki-cho, Handa 475-8611, Japan \\ ${ }^{2}$ Steel Research Laboratory, JFE Steel Corporation, Kawasaki 210-0855, Japan \\ ${ }^{3}$ Steel Research Laboratory, JFE Steel Corporation, Fukuyama 721-8510, Japan \\ ${ }^{4}$ Department of Materials Science and Engineering, Nagoya University, Nagoya 464-8603, Japan
}

This report corresponds to the third paper in three consecutive papers to know the whole sulfide precipitation in Ti-added steel by adding a new knowledge that even a trace level of copper $(0.01 \% \mathrm{Cu})$ acts as a sulfide-former. The authors show the strange phenomenon of copper sulfide in Ti-added steel in long-time-annealing in ferrite region. When annealed for short time (ex. $90 \mathrm{~s}$ ), much of $\mathrm{Cu}-\mathrm{S}$ is precipitated, but the amount of $\mathrm{Cu}-\mathrm{S}$ is small at longer-time-annealing, while TiS reduces and $\mathrm{Ti}_{4} \mathrm{C}_{2} \mathrm{~S}_{2}$ increases monotonically. This phenomenon does not mean that $\mathrm{Cu}-\mathrm{S}$ is initially formed and then dissolved away, but the $\mathrm{Cu}-\mathrm{S}$ precipitation should be interpreted as causal evidence of "(re-)solute sulfur and its reprecipitation" along the same concept in the first and the second papers. Long-time-annealing means that our proposed reaction "4TiS + $2[\mathrm{C}] \rightarrow \mathrm{Ti}_{4} \mathrm{C}_{2} \mathrm{~S}_{2}+2[\mathrm{~S}]$ " proceeds rightward and the re-solute sulfur is re-precipitated as $\mathrm{Ti}_{4} \mathrm{C}_{2} \mathrm{~S}_{2}$ (and MnS). Consequently, the amount of

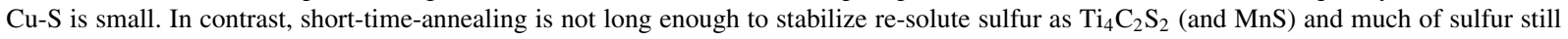
remains solute. Therefore the amount of $\mathrm{Cu}-\mathrm{S}$ is increased.

Furthermore, the phenomena in three consecutive papers is organized into an integrated concept to understand the whole sulfide precipitation in Ti-added steel in both austenite and ferrite region. [doi:10.2320/matertrans.MRA2008300]

(Received August 29, 2008; Accepted March 6, 2009; Published May 25, 2009)

Keywords: sulfide precipitation, copper sulfide, titanium carbo-sulfide, titanium sulfide, manganese sulfide, Ti-stabilized interstitial-free steel, transmission electron microscopy, quantitative chemical analysis, extracted residue, residual element, tramp element, ferrite region

\section{Introduction}

In the third report of three consecutive papers, ${ }^{1,2)}$ the authors show the strange transitional change of copper sulfide precipitation in Ti-added steel in accordance with annealingtime in ferrite region. Through the analysis, our proposed theory of $\mathrm{Cu}-\mathrm{S}$ precipitation is reinforced and also the whole phenomenon of sulfide precipitations in Ti-added steel is clearly shown in relation with $\mathrm{Cu}-\mathrm{S}$ precipitation induced by a trace level of $\mathrm{Cu}$, which has been regarded as solute in steel. In addition, the sulfide phenomena through three consecutive papers are organized into an integrated mechanism to explain the whole sulfide precipitation in both austenite and ferrite regions in Ti-added steel and also to cover the phenomenon in non-Ti-added steel.

Our proposed mechanism has a common root through three consecutive papers, ${ }^{1,2)}$ which can apply to ferrite region and austenite region in both Ti-added and non-Ti-added steel. The concept is based on three things: (1) (re-)solute sulfur exists and it is re-precipitated along the estimated reaction "4TiS $+2[\mathrm{C}] \rightarrow \mathrm{Ti}_{4} \mathrm{C}_{2} \mathrm{~S}_{2}+2[\mathrm{~S}($ re-solute $)]$ ", (2) $\mathrm{Ti}_{4} \mathrm{C}_{2} \mathrm{~S}_{2}$, $\mathrm{MnS}$ and $\mathrm{Cu}-\mathrm{S}$ are formed in ferrite region (3) the $\mathrm{Cu}-\mathrm{S}$ precipitation occurs at low temperature in ferrite region, even during WQ.

Our standpoint ${ }^{3-20)}$ and reviews of past studies have already been mentioned in details in the first report. ${ }^{1)}$ In addition, the sulfide precipitation in ferrite region in Ti-added steel has been already reviewed again in the second paper. ${ }^{2)}$

\footnotetext{
${ }^{* 1}$ Corresponding author, E-mail: y-ishiguro@jfe-steel.co.jp

*2Present address: Nippon Magnetic Dressing Co., Kurashiki 712-8074, Japan
}

In this third paper, the past studies on solute carbon in steel are mentioned below. It is related to the above mechanism "4TiS $+2[\mathrm{C}] \rightarrow \mathrm{Ti}_{4} \mathrm{C}_{2} \mathrm{~S}_{2}+2[\mathrm{~S}]$ ", in which solute carbon is a required condition.

Most of steel products include solute carbon which is not precipitated as carbide and stays as solid solution in steel. Those steel products usually occurs age-hardening (or strain aging), which means that yielding stress (YS) gets high after holding for long hours and/or at high temperature, because solute carbon diffuses into energeticunstable strained area near dislocation even at near room temperature and interferes with the mobility of dislocations. A majority of steel products are age-hardenable steel.

Although it had been exceptional, non-age-hardenable steel "IF steel" has been commonly produced through the current steelmaking technology. The sample used here is TiIF steel which stands for Ti-stabilized Interstitial-Free steel. Carbon and nitrogen are removed up to near technological limits (below 30 ppm: often referred as to ultra low carbon and/or ultra low nitrogen) and they are fully stabilized by carbide-former and nitride-former as carbide and nitride into IF steel, respectively.

Since solute carbon in IF steel does not exist by definition and IF steel is alloy-designed to stabilize all of carbon and nitrogen, it has been accepted as a common concept that agehardening does not occurs in IF steel. Also, the precipitation in Ti-IF steel has been traditionally interpreted to finish only in austenite region and not to occur in ferrite region, except for some limited papers. ${ }^{10-24)}$ In other words, carbon in Ti-IF steel has been regarded as completely stabilized as carbide. Therefore, it has to be made clear whether solute carbon 
Table 1 Chemical compositions of Ti-added steel (mass\%).

\begin{tabular}{clccccccc}
\hline sample & \multicolumn{1}{c}{ Heat Treatment } & $\mathrm{C}$ & $\mathrm{Si}$ & $\mathrm{Mn}$ & $\mathrm{Su}$ & $\mathrm{Ti}$ \\
\hline $0.04 \% \mathrm{Ti}-\mathrm{IF}$ & & $\begin{array}{l}\text { (iii) Long minute-Annealing } \\
\text { range }(\alpha)\end{array}$ & 0.0018 & 0.01 & 0.15 & 0.0074 & 0.010 \\
\cline { 3 - 8 } & & 0.0017 & 0.01 & 0.16 & 0.0062 & 0.008 & 0.064 \\
\hline
\end{tabular}

really exists in as-hot-rolled IF steel to prove that sulfide precipitation occurs along our proposed theory. ${ }^{1-20)}$

Please note that the terminology is very confusing in this scientific field. There have been some reports to mention the correlation between age-hardening and solute carbon in "Tistabilized Ultra Low Carbon Bake-Hardenable steel (TiULC-BH)", ${ }^{25,26)}$ whose chemical compositions are designed to be lower sulfur $(<20 \mathrm{ppm})$ and/or higher $\mathrm{Mn}(>1 \%)$ to obtain $\mathrm{BH}$ properties so that carbon is partially and/or weakly stabilized into $\mathrm{TiC}$ by inhibiting the precipitation of $\mathrm{Ti}_{4} \mathrm{C}_{2} \mathrm{~S}_{2} .{ }^{27-30)}$

It should be noted that BH steel, ULC steel, IF-BH steel can regarded as the same category of age-hardenable steel, but these steels are not IF steel. They include solute carbon and are designed to expect strain-age-hardening-based YS up. Strictly speaking, IF-BH steel is an inconsistent term. IF and $\mathrm{BH}$ are opposing definitions to each other, but "IF-BH steel" is regularly used for the name to mean ULC-based BH steel. The sample used here is "Ti-IF steel" and it has been believed that solute carbon does not exist. Our proposed mechanism is required for solute carbon in as-hot-rolled IF steel and therefore the existence has to be proven experimentally.

In the following section, the whole sulfide precipitation is explained by using long-annealing samples, together with the $\mathrm{Cu}-\mathrm{S}$ precipitation. The mechanism is not only derived by experimental facts but also proven conclusively.

\section{Samples and Experimental Procedure}

In understanding sulfide precipitation in Ti-added steel, the authors selected Ti-stabilized Interstitial-Free (Ti-IF) steel, because it is so simple a system that we are able to obtain a precise result of sulfide characterization.

The main characteristic is that all Ti-added samples include $0.01 \% \mathrm{Cu}$, which is inevitably present even if scraps are not used for steelmaking. The samples are from commercial-based as-hot-rolled steel which was produced through a trial operation from blast-furnace \& LD-converterbased steelmaking and continuous-casting, and then hotrolled.

As shown in Table 1, the samples of (iii) with two levels of $\mathrm{Ti}$ addition $(0.04 \% \mathrm{Ti}$ and $0.06 \% \mathrm{Ti})$ were prepared to carry out research on the transitional change on sulfide precipitation in ferrite region in accordance with annealing time. They are referred to as "0.04\% Ti-IF" and "0.06\% Ti-IF", by using the Ti content. Note that the numbering intentionally starts with (iii) and the following numbering starts with (10). They are consecutive numbers from the first paper. ${ }^{1)}$

As shown in Fig. 1, samples of 0.04\% Ti-IF and 0.06\% TiIF are prepared (10) as-hot and then annealed at $850^{\circ} \mathrm{C}$ for (11) $90 \mathrm{~s} \rightarrow \mathrm{AC}$ (Air Cooling), (12) $5 \mathrm{~min} \rightarrow \mathrm{AC}$ and (13) $30 \mathrm{~min} \rightarrow \mathrm{AC}$. It should be noted that $\mathrm{AC}$ in sheet steel is as rapid as 200 to $500^{\circ} \mathrm{C} / \mathrm{s}$.

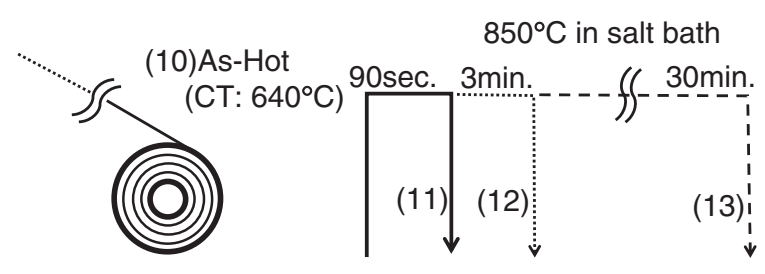

Fig. 1 Schematic diagram of heat treatment of (iii).

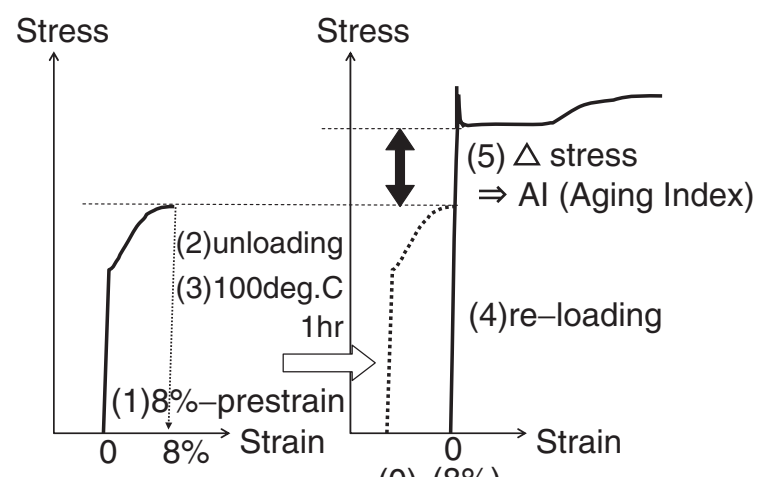

(0) $(8 \%)$

Fig. 2 Schematic procedure of Aging Index (AI) measurement.

Please note that both "0.04\% Ti-IF" and "0.06\% Ti-IF" in this paper do not correspond to "0.04\% Ti-IF" in the first and second papers ${ }^{1,2)}$ and "0.07\% Ti-IF" in the first papers, ${ }^{1)}$ respectively. Each element slightly differs, but they are referred to as "0.04\% Ti-IF" and "0.06\% Ti-IF", because steel product has an allowable range of chemical compositions in real production and can be regarded as same steel sheets within an allowance.

Experiments were carried out mainly through two methods: (a) microanalysis with the use of a Transmission Electron Microscope (TEM) and its analytical spectrometric gears and (b) quantitative chemical analysis of each sulfide ("Tai-Betsu analysis" in a Japanese technical term) with the application of extracted residue and its dissolution technique. These two methods are shown in detail in the first report ${ }^{1)}$ of three consecutive papers. ${ }^{1,2)}$

In addition, the (iii) as-hot samples were evaluated by (c) Aging Index (AI) through a mechanical evaluation technique to estimate the existence of solute carbon. This experiment is required for the discussion of the estimated mechanism of the first reaction in our proposed mechanism. ${ }^{2)}$ The AI procedure is based on a conventional method as shown in Fig. 2: (1) $8 \%$-pre-strain is applied in a tensile test and (2) then tension is unloaded, (3) the sample is kept at $100^{\circ} \mathrm{C}$ for $1 \mathrm{~h}$ and (4) the tensile test is performed again. (5) The increase in stress corresponds to "AI". "AI $>0$ " indicates that the sample contains solute carbon, while "AI $=0$ " indicates that the carbon and/or nitrogen are fully stabilized as carbide and nitride. 


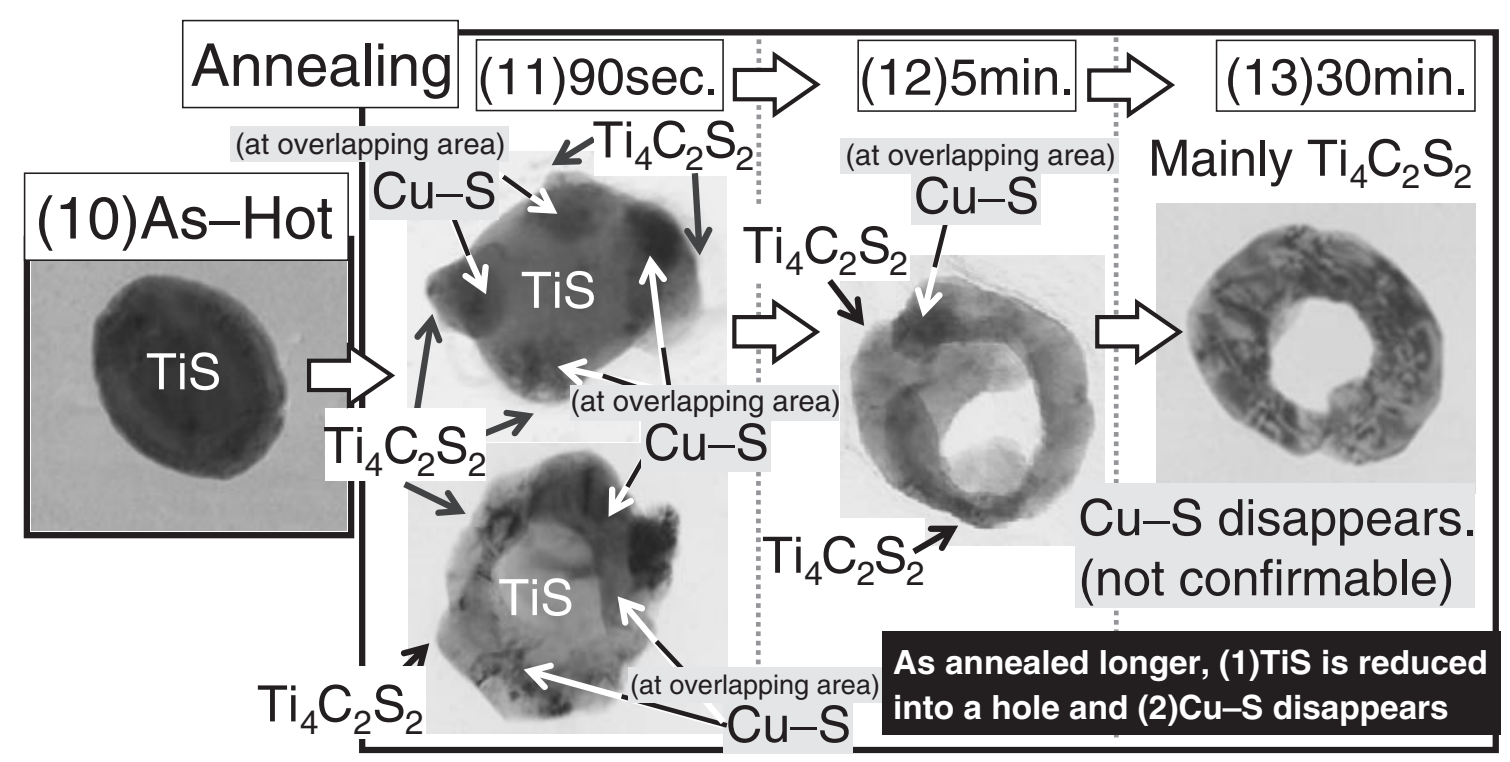

Fig. 3 Typical images of transitional morphological change of multi-precipitate-combined sulfide by long-time-annealing in Ti-added steel.

\section{Results}

\subsection{Transitional change of sulfide precipitation in long- time-ferrite-annealed $0.04 \% \mathrm{Ti}$-IF and $0.06 \% \mathrm{Ti}-\mathrm{IF}$ samples}

In this section, a transitional change of sulfide at $850^{\circ} \mathrm{C}$ is discussed. The transition of sulfide precipitation in $0.04 \% \mathrm{Ti}-\mathrm{IF}$ and $0.06 \% \mathrm{Ti}-\mathrm{IF}$ is studied by using (10) as-hot samples and annealed samples at $850^{\circ} \mathrm{C}$ for (11) $90 \mathrm{~s} \rightarrow \mathrm{AC}$ (Air Cooling), (12) $5 \mathrm{~min} \rightarrow \mathrm{AC}$ and (13) $30 \mathrm{~min} \rightarrow \mathrm{AC}$. It should be noted that $\mathrm{AC}$ in sheet steel results in cooling as rapid as 200 to $500^{\circ} \mathrm{C} / \mathrm{s}$.

First of all, a typical example of transitional change is shown in Fig. 3 to provide a simple overview of transitional morphological appearances. Detailed morphological changes in $0.04 \% \mathrm{Ti}$-IF and $0.06 \% \mathrm{Ti}$-IF samples are shown in Figs. 5 and 6 , respectively.

In studying a series of TEM micrographs in Fig. 3, the authors have to call attention to a few special points in advance. It should be noted that examples in Fig. 3 are composed of picked-up "typical sulfides" from Ti-stabilized IF steel with various Ti additions and annealing temperatures, which are not limited in $0.04 \% \mathrm{Ti}$-IF nor $0.06 \% \mathrm{Ti}$-IF in this third paper. In addition, each sulfide dares to be adjusted to almost the same size and the magnification is different in each image. The real size is approximately 150 to $400 \mathrm{~nm}$. Therefore, Fig. 3 shows how the sulfide in Ti-added steel changes morphologically and compositionally as the annealing is done for longer time.

In as-hot sample, TiS is the main sulfide and its morphology is round-shaped or oval-shaped. The surface layer is not smooth and TiS sometimes accompanies a partially-attached tiny-sized precipitate or a thinly-coated frilled structure. By annealing for a short time, for example, for $90 \mathrm{~s}$, the sulfide is changed into a multi-precipitatecombined sulfide: TiS is located in the center, $\mathrm{Ti}_{4} \mathrm{C}_{2} \mathrm{~S}_{2}$ are formed as a bulge-shaped precipitate partially attaching on $\mathrm{TiS}$, and $\mathrm{Cu}-\mathrm{S}$ is observed on some of the overlapped areas between TiS and $\mathrm{Ti}_{4} \mathrm{C}_{2} \mathrm{~S}_{2}$. Through long-time-annealing, the sulfide eventually changes to "donut-shaped" and/or "croissant-shaped (crescent-roll-shaped)". TiS, which used to exist at the center of a multi-precipitate-combined sulfide in the 90 s-annealed sample, disappears or gets small and thin, finally leaving a hole. Each bulge-shaped $\mathrm{Ti}_{4} \mathrm{C}_{2} \mathrm{~S}_{2}$ precipitate grows larger and is mutually combined together. Interestingly, $\mathrm{Cu}-\mathrm{S}$ is hardly confirmed in 30 min-annealed samples, especially in $0.06 \% \mathrm{Ti}-\mathrm{IF}$.

Although shown as typical examples in Fig. 3, all longtime-annealed sulfides are not always observed as "donutshaped" nor "croissant-shaped (crescent-roll-shaped)" and some of them are somewhat deformed. As explained in Fig. 4 by using a donut, such a complex-shaped multi-precipitatecombined sulfide has a 3-dimensional configuration and it is often observed as a different shape (2-dimensional-projected image) in accordance with the viewing angle. Therefore, the shape cannot be defined by a few TEM micrographs and it should be judged in a comprehensive manner by using many data. For the same reason, the size of these sulfides cannot be defined by a few TEM micrographs, either.

Detailed TEM micrographs of $0.04 \% \mathrm{Ti}$-IF and $0.06 \% \mathrm{Ti}-$ IF samples are shown in Figs. 5 and 6, respectively. Basically, the similar transitional change occurs and the strange phenomenon of $\mathrm{Cu}-\mathrm{S}$ is also confirmed. The only difference is the sulfide in the as-hot sample. The sulfide in $0.04 \% \mathrm{Ti}$-IF sample is composed mainly of TiS, while the sulfide in $0.06 \%$ Ti-IF sample has thinly-coated frilled other sulfides and/or partially-attached tiny-sized other sulfides on TiS.

From a chemical analytical point of view, Tai-Betsu analysis of each sulfide is shown in Fig. 7. Basically, the tendency reflects the TEM observations of Figs. 3, 5 and 6. As mentioned in TEM micrographs, the interesting thing is the $\mathrm{Cu}-\mathrm{S}$ precipitation phenomenon. $\mathrm{Cu}-\mathrm{S}$ is rarely confirmed in as-hot sample, and the amount of $\mathrm{Cu}-\mathrm{S}$ is considerably precipitated at short-annealing $\left(850^{\circ} \mathrm{C}\right.$ for $\left.90 \mathrm{~s}\right)$, but it decreases at long-annealing $\left(850^{\circ} \mathrm{C}\right.$ for $\left.30 \mathrm{~min}\right)$. 


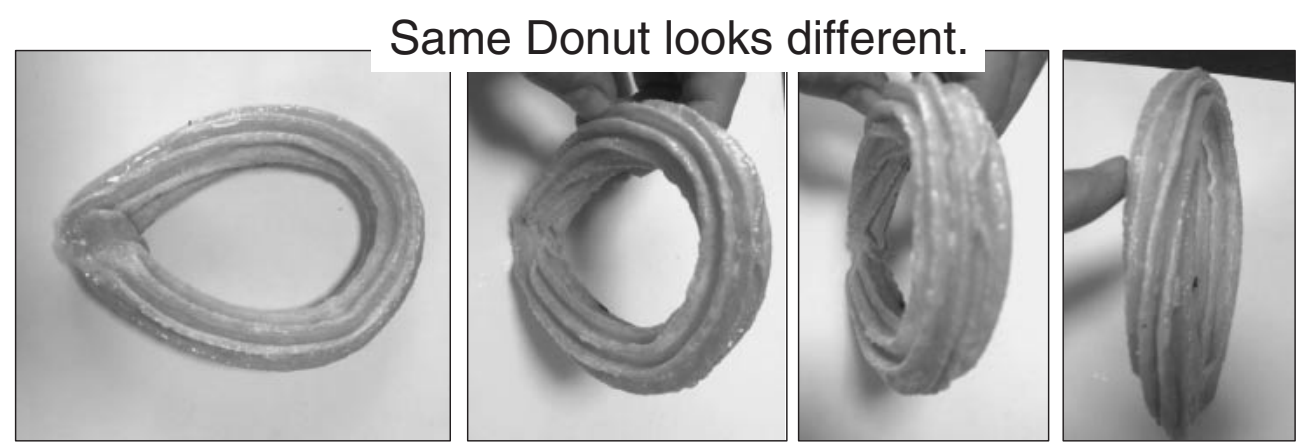

Fig. 4 2-dimensional projected images of 3-dimensional configuration from different angles, by using a "donut".

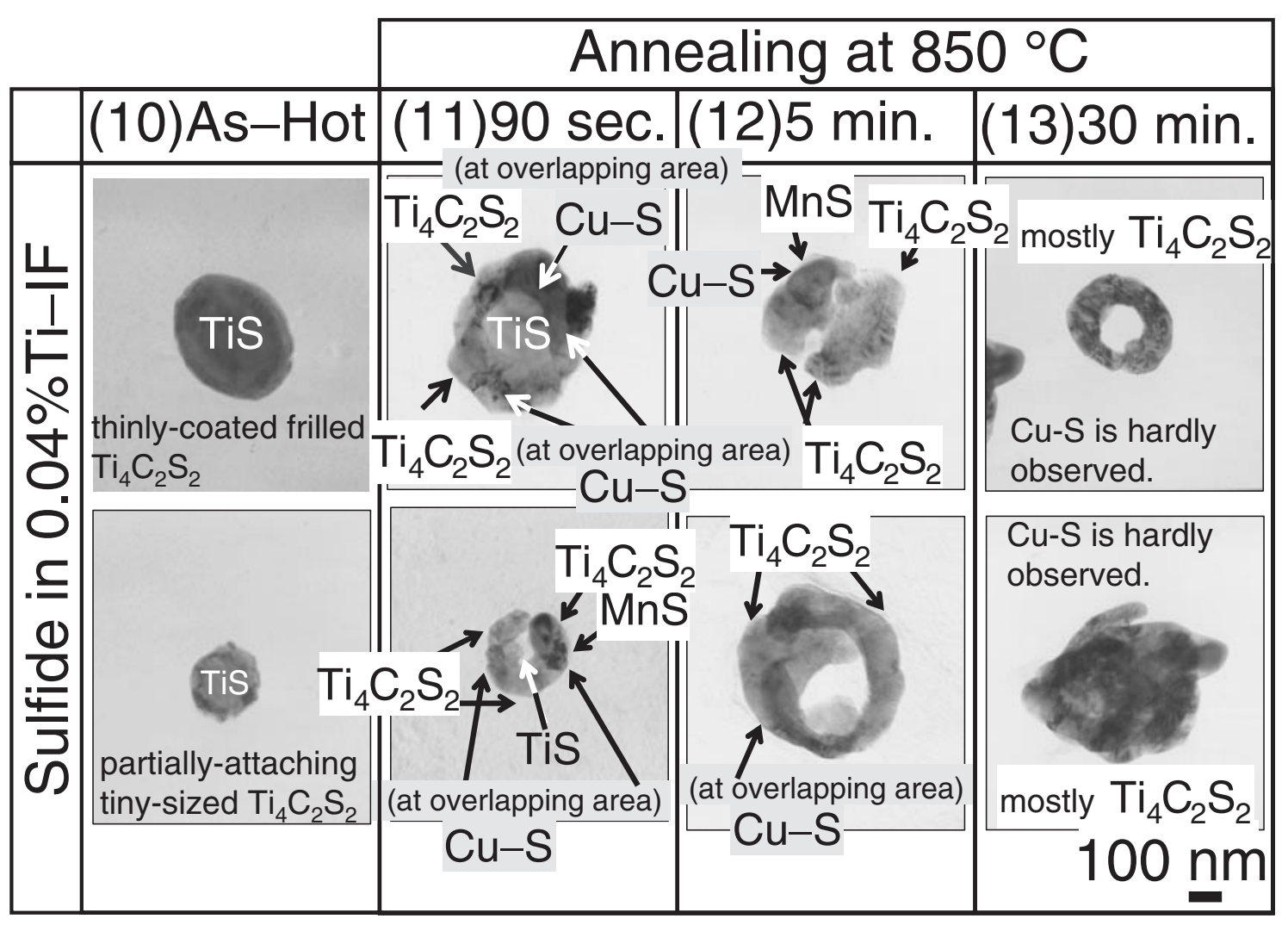

Fig. 5 Transitional morphological change in accordance of annealing time in 0.04\% Ti-IF.

The following explanation is general description of the whole sulfide precipitations.

In both $0.04 \% \mathrm{Ti}-\mathrm{IF}$ and $0.06 \% \mathrm{Ti}-\mathrm{IF}$, as-hot samples are composed mainly of TiS. Through following 90 s-annealing, TiS "decreases", and $\mathrm{Ti}_{4} \mathrm{C}_{2} \mathrm{~S}_{2}, \mathrm{MnS}$ and $\mathrm{Cu}-\mathrm{S}$ "increase" in both steels. The distinction in the $90 \mathrm{~s}$-annealed samples of both steels is the content of " $\mathrm{S}$ as $\mathrm{Cu}-\mathrm{S}$ "; 0.04\% Ti-IF sample has more $\mathrm{Cu}-\mathrm{S}$ than $0.06 \% \mathrm{Ti}-\mathrm{IF}$ sample. When annealed for longer minutes (5 to $30 \mathrm{~min}$ ), TiS decreases, $\mathrm{Ti}_{4} \mathrm{C}_{2} \mathrm{~S}_{2}$ and $\mathrm{MnS}$ increase, but conversely $\mathrm{Cu}-\mathrm{S}$ "decreases" in the 0.04\% Ti-IF sample, and, in contrast, TiS, $\mathrm{MnS}$ and $\mathrm{Cu}-\mathrm{S}$ "decrease", and $\mathrm{Ti}_{4} \mathrm{C}_{2} \mathrm{~S}_{2}$ increases in the $0.06 \% \mathrm{Ti}$-IF sample.

It should be noted that the above parenthetical description of " $\mathrm{Cu}-\mathrm{S}$ decreases" is not a proper expression, because it may probably make us misunderstood that $\mathrm{Cu}-\mathrm{S}$ is initially formed and then it is dissolved and reduced. If it really occurred, it would not be possible to explain the phenomenon from the thermodynamical viewpoint. In our opinion, the $\mathrm{Cu}-\mathrm{S}$ phenomenon should be regarded as the consequence that $\mathrm{Cu}-\mathrm{S}$ can be precipitated when the preceding sulfide reactions are completed and then re-solute sulfur still exists.

The above results in Figs. 3, 5, 6 and 7 implies that $\mathrm{Cu}-\mathrm{S}$ is formed during WQ if re-solute sulfur still remains in steel, after the preceding sulfide precipitation is finished at $850^{\circ} \mathrm{C}$. That is to say, the sulfide precipitation can be interpreted along the same mechanism in the first and the second papers that (re-)solute sulfur exists and it is re-precipitated at low temperature in ferrite region. ${ }^{1,2)}$

\subsection{Aging Index of as-hot-rolled 0.04Ti-IF and 0.06Ti-IF steel}

As mentioned in the second paper, ${ }^{2)}$ the authors has explained the sulfide precipitation in ferrite region in $\mathrm{Ti}$ added steel by using the chemical reaction " $4 \mathrm{TiS}+2$ [solute 


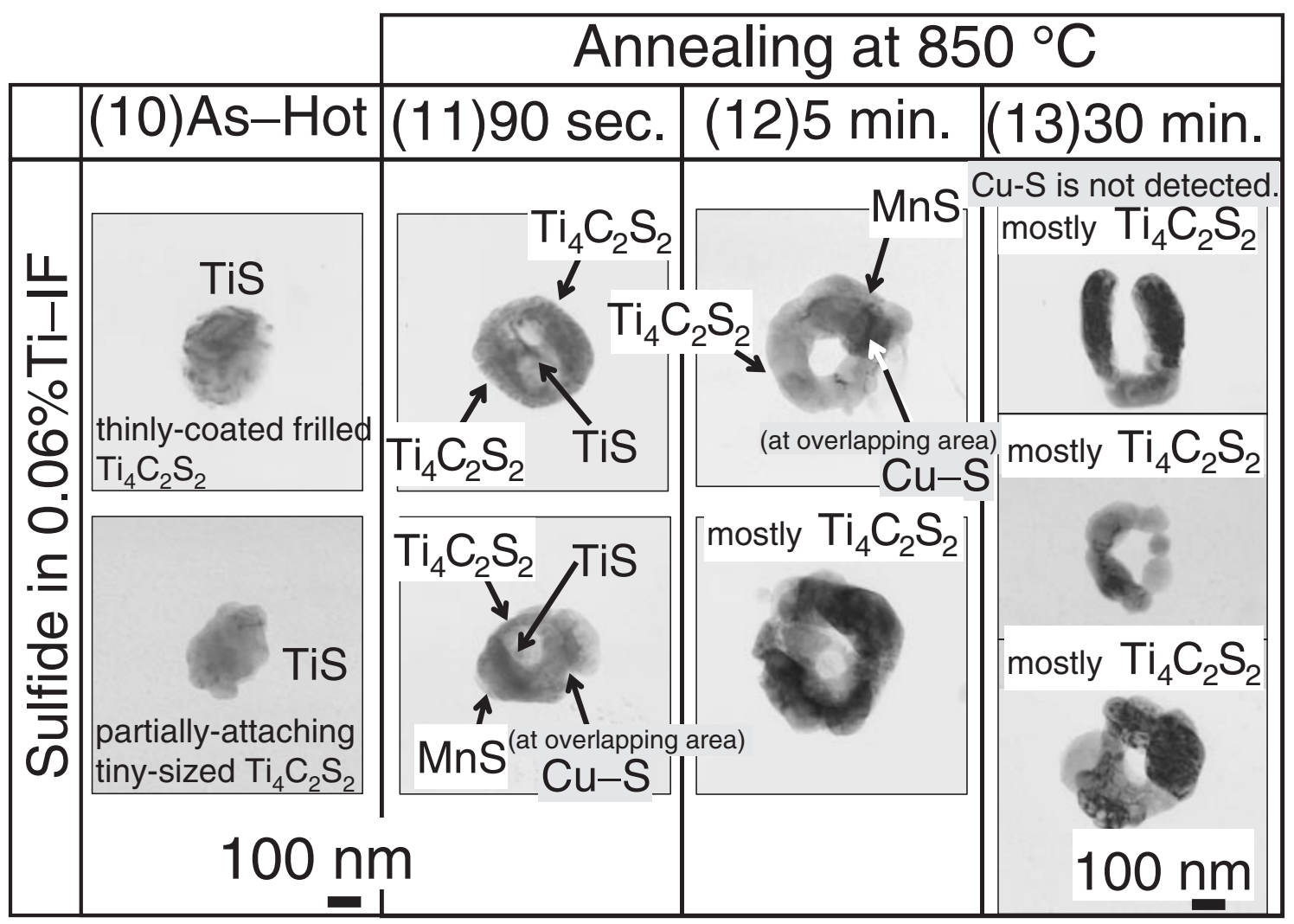

Fig. 6 Transitional morphological change in accordance of annealing time in $0.07 \% \mathrm{Ti}$-IF.

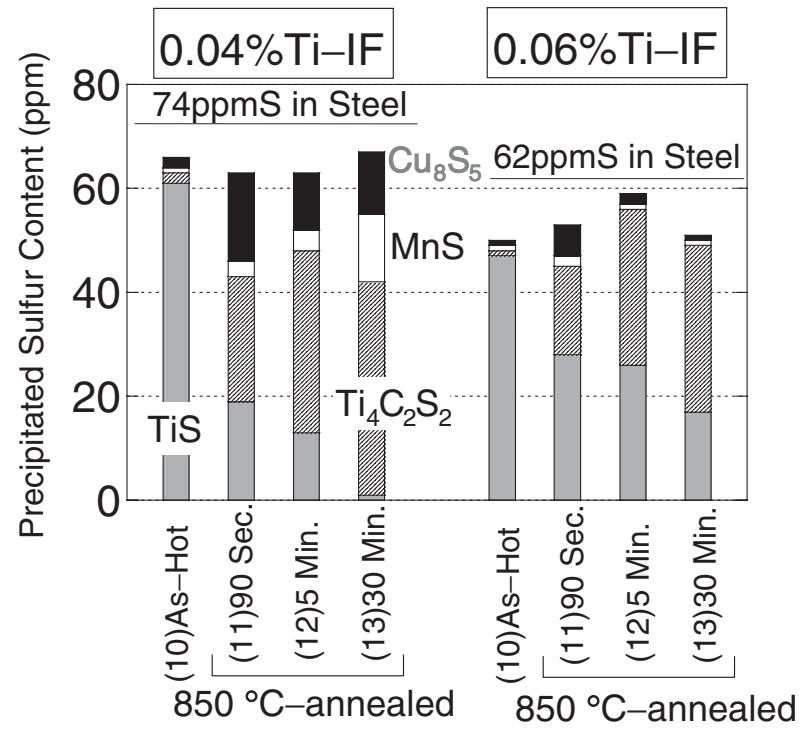

Fig. 7 Annealing-time-dependent change of sulfide precipitation in TaiBetsu analysis in $0.04 \%$ Ti-IF and $0.06 \%$ Ti-IF

$\mathrm{C}] \rightarrow \mathrm{Ti}_{4} \mathrm{C}_{2} \mathrm{~S}_{2}+2$ [solute $\mathrm{S}$ ]". However, this chemical reaction is required for "solute carbon" in Ti-added steel when the reaction occurs.

Through three consecutive papers, Ti-stabilized IF steels are used for a series of experiments. Judging from the name "IF steel", or Interstitial-atom-Free steel, all interstitial elements, such as carbon and nitrogen, have to be stabilized as precipitates. In reality, however, solute carbon exists in the as-hot sample of recently-produced Ti-stabilized IF steel.
Figure 8 shows strain-stress curves of Aging Index (AI) measurements in both $0.04 \% \mathrm{Ti}-\mathrm{IF}$ and $0.06 \% \mathrm{Ti}-\mathrm{IF}$, which are evaluated as a lower-yielding-strength-based strength increase through a subtraction of " $8 \%$ pre-strained strength" from "yielding strength in tensile test of a heat-treated sample at $100^{\circ} \mathrm{C}$ for $1 \mathrm{~h}$ after $8 \%$ pre-strained". The Aging Index (AI) of $0.04 \% \mathrm{Ti}-\mathrm{IF}$ and $0.06 \% \mathrm{Ti}-\mathrm{IF}$ are the same values of $33 \mathrm{MPa}$.

"IF steel" is alloy-designed to stabilize all of the interstitial elements as precipitates, for example, it has been controlled, for example, by using the parameters of " $\mathrm{C}(\mathrm{at} \%) /$ $\mathrm{Ti}($ at $\%)<1$ ", "[Ti $-\mathrm{N} / 14 \times 48($ used for $\mathrm{TiN})-\mathrm{S} / 32 \times$ 48 (used for $\mathrm{TiS})] / 48 \times 12-\mathrm{C}>0($ mass $\%)$ (enough to stabilize carbon)" and so on. Figure 8 means that as-hot sample in Ti-IF contains solute carbon, and strictly speaking, as-hot steel sheets of $0.04 \% \mathrm{Ti}$-IF and $0.06 \% \mathrm{Ti}$-IF in this paper can be regarded literally as "non-IF steel". In other words, the data in Fig. 8 proves the existence of "solute carbon" in as-hot Ti-IF steel which is regarded as the required condition in our proposed mechanism " $4 \mathrm{TiS}+2$ [solute $\mathrm{C}$ ] $\rightarrow$ $\mathrm{Ti}_{4} \mathrm{C}_{2} \mathrm{~S}_{2}+2[$ solute $\mathrm{S}$ ]".

\section{Discussions}

\subsection{Mechanism of sulfide precipitation at long-anneal- ing of ferrite region in Ti-added steel and interpre- tation of $\mathrm{Cu}-\mathrm{S}$ precipitation}

The same mechanism in the first ${ }^{1)}$ and the second papers ${ }^{2)}$ is applied to these phenomena. The concept is based on the idea that (re-)solute sulfur comes out in the first reaction and it is re-precipitated in the second reaction. 

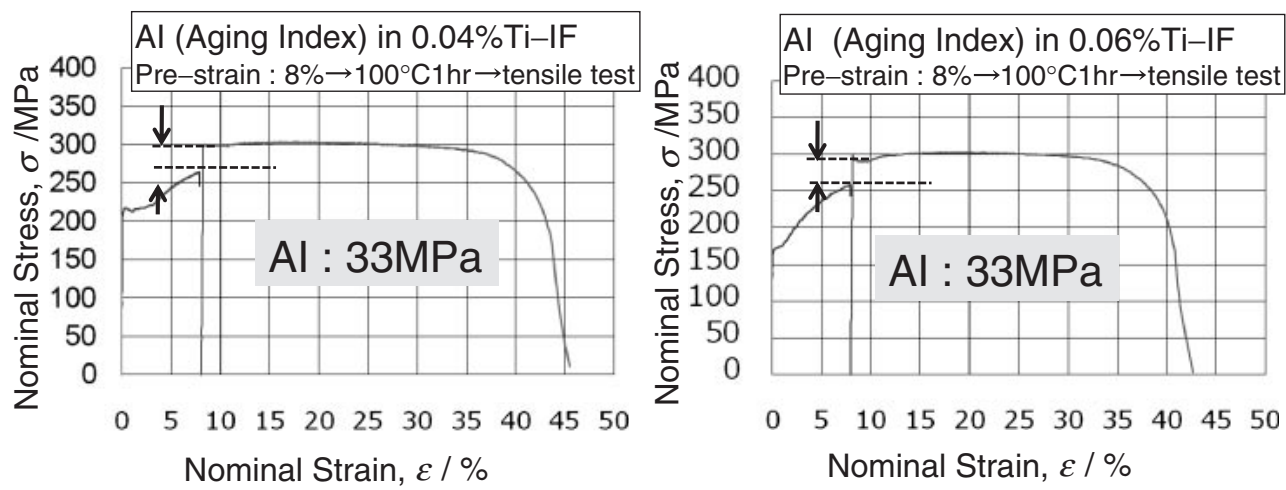

Fig. 8 Aging Index of as-hot-rolled 0.04\% Ti-IF and 0.06\% Ti-IF steel.

The following mechanism needs the existence of alreadyprecipitated TiS and solute carbon, both of which have been proved experimentally. For the sake of simplicity, the mechanism is divided into two reactions and the following "re-solute sulfur" is assumed as virtual existence.

The first reaction is a trigger to reconfigure sulfide precipitation, in which already-precipitated TiS is reacted into "first $\mathrm{Ti}_{4} \mathrm{C}_{2} \mathrm{~S}_{2}$ " and simultaneously "re-solute sulfur" comes out. In the second reaction, the "re-solute sulfur" is reprecipitated as one of three candidates: "second $\mathrm{Ti}_{4} \mathrm{C}_{2} \mathrm{~S}_{2}$ ", $\mathrm{MnS}$ and $\mathrm{Cu}-\mathrm{S}$.

[First reaction]

$$
(1 \mathrm{st}) 4 \mathrm{TiS}+2[\mathrm{C}] \rightarrow \mathrm{Ti}_{4} \mathrm{C}_{2} \mathrm{~S}_{2} \text { (first) }+2[\mathrm{~S} \text { (re-solute) }]
$$

[Second reaction] (three possible candidates)

(2nd-1) [re-solute $\mathrm{S}]+4[\mathrm{Ti}]+2[\mathrm{C}] \rightarrow \mathrm{Ti}_{4} \mathrm{C}_{2} \mathrm{~S}_{2}$ (second)

(2nd-2) [re-solute $\mathrm{S}]+[\mathrm{Mn}] \rightarrow \mathrm{MnS}$

(2nd-3) [re-solute $\mathrm{S}]+[\mathrm{Cu}] \rightarrow \mathrm{Cu}-\mathrm{S}$

In our opinion, the first reaction and the second reaction are basically one-way continuous precipitations. Since solute sulfur cannot be found experimentally, it is thought that re-solute sulfur is quickly re-precipitated as other sulfides, as soon as it appears along the first reaction. Probably, these two reactions is correlated through Le Chatelier's law.

The parameters for the first reaction are the amount of solute carbon and temperature and time in heat-treatment. The ones for the second reaction are the amount of solute sulfur, temperature and time in heat-treatment, the amount of solute carbon and the amount of each sulfide-former element. The mechanism to reconfigure sulfide precipitation is dependent on many mutually-related factors. Since it has been proven in Fig. 7 in 3.2 section that solute carbon exists in the Ti-IF steel used here, our mechanism does not have any obstacles to explain the phenomena.

By applying the above mechanism, we can interpret a strange phenomenon on the $\mathrm{Cu}-\mathrm{S}$ precipitation in Tai-Betsu analysis in Fig. 7 that the $\mathrm{Cu}-\mathrm{S}$ content is large in $90 \mathrm{~s}-$ annealed sample but it is "reduced (hard to observe)" in 30 min-annealed sample. The important point is how far rightward the first reaction proceeds during heat treatment and then what stabilizes the "re-solute sulfur" along the second reaction according to thermodynamics.

At short-annealing, the (1st) reaction proceeds rightward and simultaneously "re-solute sulfur" comes out. The annealing time is so short that the (2nd-1) and (2nd-2) reactions cannot stabilize all of the "re-solute sulfur". The remaining "re-solute sulfur" is stabilized as $\mathrm{Cu}-\mathrm{S}$ in ferrite region during WQ. In contrast, at long-annealing, the (1st) reaction proceeds further rightward and simultaneously more "re-solute sulfur" comes out. The annealing time is so long that the (2nd-1) and (2nd-2) reactions can stabilize much of the "re-solute sulfur". The remaining "re-solute sulfur" gets lower and therefore the amount of $\mathrm{Cu}-\mathrm{S}$ is reduced. The $\mathrm{Cu}-\mathrm{S}$ phenomenon should be regarded as a consequence that (re-)solute sulfur is reduced by stabilizing with various sulfide-former through the thermodynamics and the remaining solute sulfur is precipitated by a small amount of $\mathrm{Cu}$ at the end of a series of sulfide precipitations. It is not thermodynamically possible to interpret literally that $\mathrm{Cu}-\mathrm{S}$ is initially precipitated at short-annealing and dissolved away at longannealing.

At the (1st) reaction of the change from TiS to $\mathrm{Ti}_{4} \mathrm{C}_{2} \mathrm{~S}_{2}$, precipitated sulfur is reduced by half in quantity. By using this knowledge, sulfide precipitation can be understood more precisely. The method for interpretation has mentioned in Fig. 11 in the second paper. ${ }^{2)}$

As shown in Fig. 9, through the comparison between 90 s-annealed and 30 min-annealed $0.04 \%$ Ti-IF, it is concluded that the longer-annealed sample has both "first" and "second $\mathrm{Ti}_{4} \mathrm{C}_{2} \mathrm{~S}_{2}$ ". In contrast, it can be estimated that the shorter-annealed sample has only "first $\mathrm{Ti}_{4} \mathrm{C}_{2} \mathrm{~S}_{2}$ " and "re-solute sulfur" is stabilized as mainly $\mathrm{Cu}-\mathrm{S}$ during WQ.

The above mechanism has a broad range of applications to explain the whole sulfide precipitation in ferrite region in Ti-added steel and to interpret the role of $\mathrm{Cu}-\mathrm{S}$ precipitation. As compared to the past studies, ${ }^{21-24)}$ our viewpoint can be regarded as innovative and comprehensive. As mentioned in "Purpose of our studies and reviews of past reports" in the first paper" and in "Introduction" in the second paper, ${ }^{2)}$ the sulfide precipitation in ferrite region has been exceptionally reported only by $\mathrm{K}$. Yamada et $a .^{21,23)}$ and H. Murakami et al., ${ }^{22,24)}$ but their mechanisms are mutually contradictory and can be restrictedly used only for their reporting phenomena. In contrast, our mechanism has a wide application to explain the whole sulfide precipitation phenomena in ferrite region in $\mathrm{Ti}_{-}$ added steel and their reported phenomena can be also interpreted logically. 


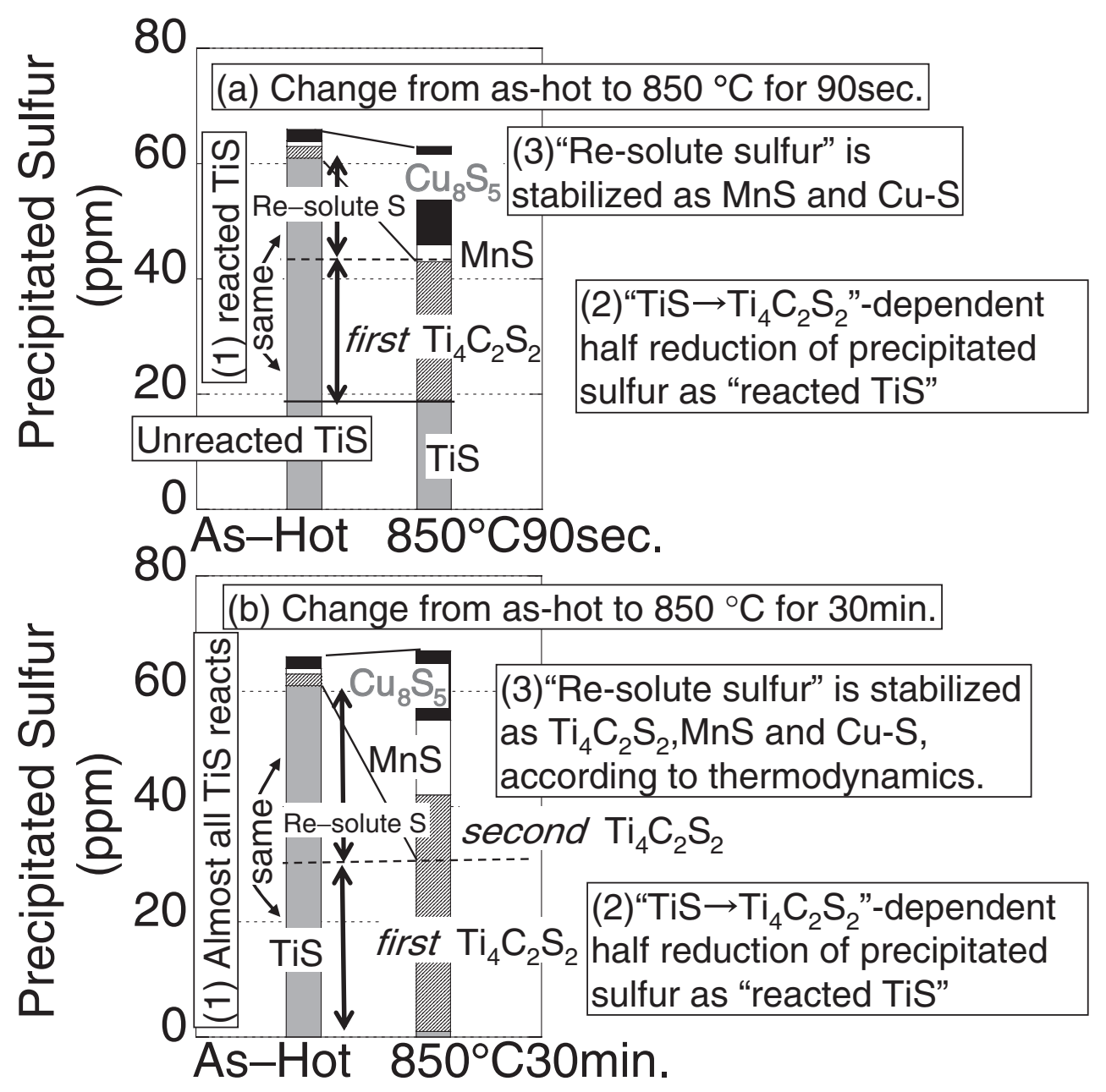

Fig. 9 Mechanism "4TiS $+2[\mathrm{C}] \rightarrow \mathrm{Ti}_{4} \mathrm{C}_{2} \mathrm{~S}_{2}+2[\mathrm{~S}]$ "-based interpretation of sulfide precipitations to (a) as-hot \& $850^{\circ} \mathrm{C}$ for $90 \mathrm{~s}$ and (b) as-hot $\& 850^{\circ} \mathrm{C}$ for $30 \mathrm{~min}$.

\subsection{Integrated mechanism of sulfide precipitation in steel}

The authors have already shown the mechanism of Tiadded steel in austenite region with the subsequent cooling in the first paper $^{1)}$ and the theory in ferrite region in the second ${ }^{2)}$ and this third papers. In this section, these proposed mechanisms are integrated into a unified concept to explain all the sulfide precipitation phenomena in steel.

First of all, the mechanism in Ti-added steel is mentioned. Figure 10 is a schematic diagram to explain sulfide precipitation in Ti-added steel. The unified mechanism is based on the newly-added concept of (\#3) for ferrite region and (\#2-2) for austenite region, in addition to the traditional concept of (\#1) and (\#2-1). Of particular note is newly-pointed ( $\alpha-1 \mathrm{st})$ and $(\gamma-1$ st) of TiS-based reconfiguration and ( $\alpha-2$ nd-3) of $\mathrm{Cu}-\mathrm{S}$ precipitation in ferrite region.

The fundamental of this integrated theory is based on the combination phenomenon of (re-)solute sulfur and its reprecipitation. As mentioned through three consecutive papers, ${ }^{1,2)}$ "re-solute sulfur" is from TiS-based reaction which is " $4 \mathrm{TiS}+2[\mathrm{C}] \rightarrow \mathrm{Ti}_{4} \mathrm{C}_{2} \mathrm{~S}_{2}+2[\mathrm{~S}$ (re-solute)]". It should be noted that "re-solute sulfur" is virtual existence for explanation. When "re-solute sulfur" comes out to matrix, it will be quickly re-precipitated by one of sulfide- former elements into sulfide. When re-solute sulfur still remains after the preceding precipitations are completed, it is re-stabilized as $\mathrm{Cu}-\mathrm{S}$ even during WQ. Therefore, it is thought that re-solute sulfur cannot be confirmed when observed a sample at room temperature. In contrast, "solute sulfur (in narrow meaning)" is based on the remaining free sulfur which cannot be stabilized beyond precipitatable sulfur limit, when heat-treated at high temperature.

Our group points out that the reactions of (\#1) to (\#3) are important chemical reactions to deepen understanding of sulfide precipitation in Ti-added steel, especially (\#3) in ferrite region. In addition, the reaction of ( $\alpha$-2nd-3) in (\#3), the $\mathrm{Cu}-\mathrm{S}$ precipitation, should be understood as one of the important reactions among mutually-related sulfide precipitations, especially as the final sulfide precipitation to stabilize both "solute sulfur" and "re-solute sulfur". It can be interpreted that $\mathrm{Cu}$ acts as a strong sulfide-former to stabilize (re-)solute sulfur along the mechanism of ( $\alpha$-2nd-3) in (\#3) even if $\mathrm{Cu}$ is at a trace level of $0.01 \%$.

It has been proven experimentally through three consecutive papers that the $(\# 1)$ reaction and the $(\# 3)$ reaction really occur in austenite and ferrite region, respectively. ${ }^{1,2}$ )

The traditional concept in Ti-added steel is also shown in both the (\#1) and the (\#2-1) of the schematic diagram in 


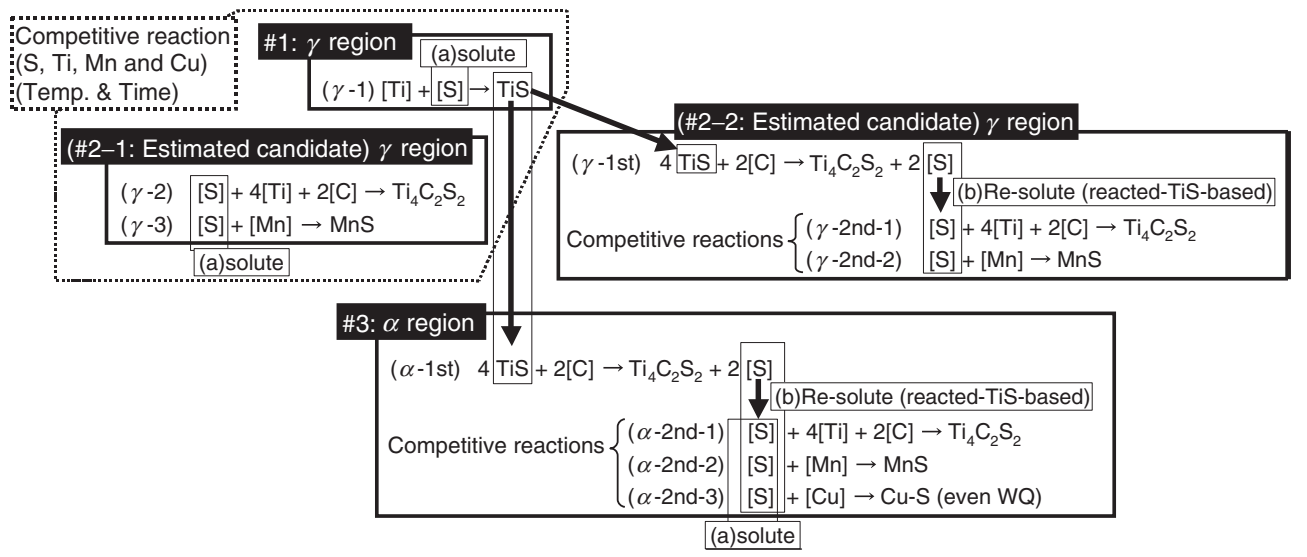

Fig. 10 Integrated mechanism of sulfide precipitation in Ti-added steel.

Fig. 10. In the past studies, the focus of attention has been targeted to only the three sulfide precipitations of $(\gamma-1) \mathrm{TiS}$ in $(\# 1),(\gamma-2) \mathrm{Ti}_{4} \mathrm{C}_{2} \mathrm{~S}_{2}$ in (\#2-1) and $(\gamma-3) \mathrm{MnS}$ in $(\# 2-1)$. Three candidates of sulfide precipitation in austenite region are competitive reactions to stabilize solute sulfur at high temperature. Which precipitate is formed most predominantly is dependent on temperature and time in heat-treatment and the amounts of sulfide-formers ( $\mathrm{Ti}$ and $\mathrm{Mn}$ ). It has been still believed that this scientific field has been regarded as investigated thoroughly, and that these phenomena can be predicted through equilibrium thermodynamical calculation in austenite region.

Although the conventional theory is well established, the authors present another estimated reaction in austenite region. There seems to be no direct evidence to prove whether either reaction of (\#2-1) or (\#2-2) occurs in austenite region or whether both precipitations proceed, but we think that the (\#2-2) reaction really occurs. Judging from TEM micrographs of as-cast and its austenite-heat-treated Ti-IF in Fig. 6 in the first paper, ${ }^{1)}$ it is microscopically evident that rod-like-structured $\mathrm{TiS}-\mathrm{Ti}_{4} \mathrm{C}_{2} \mathrm{~S}_{2}$-combined sulfides in as-cast sample always have overlapping points or TiS in austeniteheat-treated sample is uniformly covered with $\mathrm{Ti}_{4} \mathrm{C}_{2} \mathrm{~S}_{2}$. If only the $(\gamma-2)$ reaction in (\#2-1) occurs along the traditional concept, it will be difficult to explain why any free-standing $\mathrm{Ti}_{4} \mathrm{C}_{2} \mathrm{~S}_{2}$ does not exist in as-cast and austenite-heat-treated Ti-added steel in the first paper. ${ }^{1)}$ Therefore, the traditional phenomenon may be also interpreted through the (\#2-2) reaction, which means the $(\# 3)$ reaction can be extended to the precipitation in austenite region.

The above mechanism can also cover the phenomena in non-Ti-added steel. If Ti-related matters are removed from proposed reactions in Fig. 10, the sulfide precipitation in non-Ti-added steel can be interpreted. As mentioned in our paper in non-Ti-added steel, ${ }^{3,9-15)}$ when sulfur and Mn are low in content, especially in recent-produced steel, Mn can no longer stabilize all of sulfur and therefore $\mathrm{Cu}-\mathrm{S}$ should be interpreted to stabilize such remaining solute sulfur.

The authors think that the whole sulfide precipitation can be understood more precisely through this integrated mechanism, especially the phenomenon in ferrite region. The key point for interpretation is that $\mathrm{Cu}-\mathrm{S}$ precipitation occurs at low temperature in ferrite region, even during WQ. In other words, WQ technique has been regarded as a convenient method to freeze precipitation just before WQ, but exceptionally $\mathrm{Cu}-\mathrm{S}$ precipitation cannot be stopped by WQ, although it may be difficult to accept such a challenging phenomenon intuitively.

\subsection{Expected matters derived by integrated mechanism}

The following five things can be expected or still remain mysterious in the above integrated concept.

(1) A small amount of $\mathrm{Cu}$ in steel is expected to diffuse faster than published data. ${ }^{31)}$

(2) What temperature is $\mathrm{Cu}-\mathrm{S}$ formed at?

(3) $\mathrm{Cu}-\mathrm{S}$ is independently formed and separation-based precipitation does not occur from complete-solidsolution-typed precipitate, for example, $(\mathrm{Mn}, \mathrm{Cu}) \mathrm{S}$, $(\mathrm{Mn}, \mathrm{Cu})(\mathrm{O}, \mathrm{S}) . \mathrm{Cu}-\mathrm{S}$ is precipitated as free-standingtyped and/or coating-typed in non-Ti-added steel and at some of overlapping area between TiS and $\mathrm{Ti}_{4} \mathrm{C}_{2} \mathrm{~S}_{2}$ in TiS- $\mathrm{Ti}_{4} \mathrm{C}_{2} \mathrm{~S}_{2}$-combined sulfide in Ti-added steel.

(4) Our mechanism is completely different from any other published data. Why did the past studies conclude that $\mathrm{Cu}-\mathrm{S}$ is formed at temperatures as high as steel is melted? Or is it possible to describe $\mathrm{Cu}-\mathrm{S}$ phenomenon thermodynamically?

(5) All precipitates should be crystallographically energetic-stable form in shape, for example, round-shaped, oval-shaped, cubic, polygonal-shaped, or habit-planesurrounding-shaped. Why does multi-precipitate-combined sulfide, mainly $\mathrm{TiS}-\mathrm{Ti}_{4} \mathrm{C}_{2} \mathrm{~S}_{2}$-combined sulfide, have a strange irregular shape? Why does such an energetic-unstable shape exist?

In regard to (1), although mentioned in the second paper, ${ }^{2)}$ our experimental results lead to the conclusion that a small amount of $\mathrm{Cu}$ in steel can diffuse very fast. The prediction goes against the established concept that the diffusion of substitutional element is almost the same to Fe-self-diffusion, ${ }^{31)}$ but our observing phenomena can be regarded as one of proofs to support that $\mathrm{Cu}$ can diffuse faster. It can be thought that re-solute sulfur comes out along our proposed reaction " $4 \mathrm{TiS}+2[\mathrm{C}] \rightarrow \mathrm{Ti}_{4} \mathrm{C}_{2} \mathrm{~S}_{2}+2[\mathrm{~S}$ (re-solute)]" and it is often re-precipitated as $\mathrm{Cu}-\mathrm{S}$ at some of overlapping area in $\mathrm{TiS}_{-} \mathrm{Ti}_{4} \mathrm{C}_{2} \mathrm{~S}_{2}$-combined sulfide. The question is why sulfur stay there and $\mathrm{Cu}$ comes there and stabilizes the sulfur as $\mathrm{Cu}$ - 
$\mathrm{S}$, although sulfur is an interstitial element to diffuse faster and $\mathrm{Cu}$ is a substitutional element to diffuse at the level of $\mathrm{Fe}$ self-diffusion according to the conventional concept. We have not had a clear answer for it. Our prediction that $\mathrm{Cu}$ can diffuse very fast is inductively deduced.

Interestingly, there have been some reports in the field of irradiation-induced embrittlement in material for atomic reactors, ${ }^{32-36)}$ which mention that $\mathrm{Cu}$ diffusion is about two orders of magnitude faster than $\mathrm{Fe}$ self-diffusion and is interpreted through Self-Interstitial-Atom (SIA) mechanism, although these experiments are carried out by using $\mathrm{Fe}-1 \% \mathrm{Cu}$ or $\mathrm{Fe} / \mathrm{Cu} / \mathrm{Fe}$ diffusion pairs heat-treated at over $1000^{\circ} \mathrm{C}$. In our opinion, these phenomena have the same origin to our reports $^{1-20)}$ and each $\mathrm{Cu}$-related or $\mathrm{Cu}-\mathrm{S}$-related phenomenon is viewed from a different angle.

In regard to (2), it is true that $\mathrm{Cu}-\mathrm{S}$ is formed as the final sulfide precipitation after the all preceding reaction are completed and it can be precipitated in ferrite region during WQ, but the precise temperature has not been clear yet. The precipitation of $\mathrm{Cu}-\mathrm{S}$ surely occurs during WQ. Therefore, unfortunately, it means that there are no experimental techniques to freeze the $\mathrm{Cu}-\mathrm{S}$ precipitation.

It is thought that $\mathrm{Cu}-\mathrm{S}$ is formed at a certain temperature in ferrite region during WQ. According the experimental data in non-Ti-added steel, ${ }^{3,9-15)} \mathrm{Cu}-\mathrm{S}$ is precipitated at below $750^{\circ} \mathrm{C}$ during WQ and free-standing $\mathrm{Cu}-\mathrm{S}$ is observed easily in ashot non-Ti-added steel with CT: $620^{\circ} \mathrm{C}$. From the data in Tiadded steel, $\mathrm{Cu}-\mathrm{S}$ is formed in ferrite region during WQ. However, the authors know that $\mathrm{Cu}-\mathrm{S}$ is precipitated to some extent whatever heat treatment is done, although the data are not shown here. Therefore, we want to point out the possibility that $\mathrm{Cu}-\mathrm{S}$ is formed at quite low temperature near room temperature, such as a similar case in aging phenomena of carbon. As another similar example, it has been widely known that brass( $\mathrm{Cu}-\mathrm{Zn}$-alloy)-coating on steel code and vulcanized rubber ( $\underline{\text { sulfur }}$ ) for tire are easily combined into $\mathrm{Cu}-\mathrm{S}$ at low temperature (below 100 to $200^{\circ} \mathrm{C}$ ), ${ }^{37-40)}$ although the contents of sulfur and $\mathrm{Cu}$ are so high.

In regard to (3), it is microscopically evident that $\mathrm{Cu}-\mathrm{S}$ is independently formed through three consecutive papers. ${ }^{1,2)}$ The precipitation is not based on the separation from complete-solid-solution-typed sulfide and oxy-sulfide.

The topic of (4) is related to either the above (1) or the second reactions in our proposed mechanism in Fig. 10. Although some groups have reported the solubility product of $\mathrm{Cu}-\mathrm{S}^{41)}$ and thermodynamical data, ${ }^{42,43)}$ these data are based on WQ-method-based $\mathrm{Cu}-\mathrm{S}$ phenomenon by using intentionally-Cu-added steel. Therefore, one possibility is that $\mathrm{Cu}-\mathrm{S}$ precipitation might be misinterpreted as formed at temperature just before $\mathrm{WQ}$, or the other possibility is that $\mathrm{Cu}-\mathrm{S}$ is really formed at temperatures as high as these papers are saying, because the second reaction in our mechanism is a competitive precipitation among three candidates. When $\mathrm{Cu}$ is intentionally added, the reaction of $\mathrm{Cu}-\mathrm{S}$ may be selected to occur at high temperature.

In our opinion, it is difficult to describe the $\mathrm{Cu}-\mathrm{S}$ precipitation thermodynamically when $\mathrm{Cu}$ is at trace level. $\mathrm{Cu}-\mathrm{S}$ is formed at low temperature in ferrite region even during WQ. Therefore it means that there are no proper experimental techniques to freeze the precipitation. Addi- tionally, especially in Ti-added steel, the $\mathrm{Cu}-\mathrm{S}$ precipitation is not in equilibrium. It is influenced by the preceding sulfide precipitations and can be regarded as a time-dependent phenomenon.

In regard to (5), the strange morphology of precipitate is based on the sulfide precipitation that does not reach equilibrium in usual heat treatment. If the precipitation occurs along the first reaction in our proposed mechanism "4TiS $+2[\mathrm{C}] \rightarrow \mathrm{Ti}_{4} \mathrm{C}_{2} \mathrm{~S}_{2}+2[\mathrm{~S}]$ ", the equilibrium state means that the reaction will continue until TiS is used up. However, in most cases, TiS still remains in a multiprecipitate-combined precipitate, which means it does not reach equilibrium, that is, precipitations can be regarded as intermediate state. Therefore, it is thought that energeticunstable-irregular-shaped precipitates can exist.

\section{Summary}

The authors provide the following new concepts of sulfide precipitation in Ti-added steel, especially Ti-stabilized IF steel by using long-annealed samples, and give the integrated mechanism to interpret all the sulfide phenomena through three consecutive papers. ${ }^{1,2)}$

(1) Even a trace level of $0.01 \% \mathrm{Cu}$ can act as a sulfide-former in Ti-added steel, and $\mathrm{Cu}-\mathrm{S}$ is formed during WQ.

(2) The sulfide precipitation in both austenite and ferrite regions can be interpreted through the integrated mechanism in Fig. 10. The fundamentals of this mechanism are based on the combination effect of (re-)solute sulfur and its reprecipitation.

(3) In ferrite region, already-precipitated TiS is changed into $\mathrm{Ti}_{4} \mathrm{C}_{2} \mathrm{~S}_{2}$ and re-solute sulfur comes out, and then it is reprecipitated as three candidates of sulfides: $\mathrm{Ti}_{4} \mathrm{C}_{2} \mathrm{~S}_{2}, \mathrm{MnS}$ and $\mathrm{Cu}-\mathrm{S}$. The $\mathrm{Cu}-\mathrm{S}$ precipitation occurs only when re-solute sulfur still remains after the preceding reactions are completed. The strange phenomenon that $\mathrm{Cu}-\mathrm{S}$ disappears in long-annealed Ti-IF steel can be explained along the mechanism below, that is, much of re-solute sulfur is stabilized as $\mathrm{Ti}_{4} \mathrm{C}_{2} \mathrm{~S}_{2}$ and/or $\mathrm{MnS}$, and re-solute sulfur cannot be stabilized by $\mathrm{Cu}$.

[Our proposed mechanism in ferrite region]

[First reaction]

$$
4 \mathrm{TiS}+2[\mathrm{C}] \rightarrow \mathrm{Ti}_{4} \mathrm{C}_{2} \mathrm{~S}_{2}+2[\mathrm{~S}(\text { re-solute })]
$$

[Second reaction]

$$
\begin{aligned}
& (2 \mathrm{nd}-1)[\mathrm{S}]+4[\mathrm{Ti}]+2[\mathrm{C}] \rightarrow \mathrm{Ti}_{4} \mathrm{C}_{2} \mathrm{~S}_{2} \\
& (2 \mathrm{nd}-2)[\mathrm{S}]+[\mathrm{Mn}] \rightarrow \mathrm{MnS} \\
& (2 \mathrm{nd}-3)[\mathrm{S}]+[\mathrm{Cu}] \rightarrow \mathrm{Cu}-\mathrm{S}
\end{aligned}
$$

(4) In austenite region, it is thought that both or either of two possible reactions occurs. The one is the conventional reaction and the other reaction is the above-mentioned (3) mechanism. If the sample is cooled slowly, the precipitation also occurs in ferrite region along the above-mentioned (3) reactions

[Conventional reaction in austenite region]

$$
\begin{aligned}
& {[\mathrm{Ti}]+[\mathrm{S}] \rightarrow \mathrm{TiS}} \\
& 4[\mathrm{Ti}]+[\mathrm{S}]+2[\mathrm{C}] \rightarrow \mathrm{Ti}_{4} \mathrm{C}_{2} \mathrm{~S}_{2} \\
& {[\mathrm{Mn}]+[\mathrm{S}] \rightarrow \mathrm{MnS}}
\end{aligned}
$$


[Another reaction] (extension of the mechanism in ferrite region)

[First reaction]

$$
4 \mathrm{TiS}+2[\mathrm{C}] \rightarrow \mathrm{Ti}_{4} \mathrm{C}_{2} \mathrm{~S}_{2}+2[\mathrm{~S}]
$$

[Second reaction]

$$
\begin{aligned}
& (2 \mathrm{nd}-1)[\mathrm{S}]+4[\mathrm{Ti}]+2[\mathrm{C}] \rightarrow \mathrm{Ti}_{4} \mathrm{C}_{2} \mathrm{~S}_{2} \\
& (2 \mathrm{nd}-2)[\mathrm{S}]+[\mathrm{Mn}] \rightarrow \mathrm{MnS} \\
& (2 \mathrm{nd}-3)[\mathrm{S}]+[\mathrm{Cu}] \rightarrow \mathrm{Cu}-\mathrm{S}
\end{aligned}
$$

(5) In non-Ti-added steel, the sulfide precipitation should be interpreted along Ti-related-phenomena-exclusive abovementioned (3) and (4) mechanisms. The solute sulfur is based on the phenomenon that Mn cannot stabilize all of sulfur in steel. When sulfur and Mn are low in content, Mn can no longer stabilize all of sulfur and remaining sulfur is precipitated as $\mathrm{Cu}-\mathrm{S}$ by small amount of $\mathrm{Cu}$.

\section{Acknowledgements}

The authors would like to thank Dr. Kei Sakata (JFE Steel Corporation) for the opportunity to conduct research on such a pure-metallurgy-truth-seeking theme and for valuable discussion. We would also like to thank Dr. Yoshihiro Hosoya (JFE Steel Corp.) for long support of this research and helpful mutual communications.

We must thank Mr. Yoshikazu Kawabata, Dr. Mitsuo Kimura, Mr. Takatoshi Okabe, Mr. Shunsuke Toyoda and other members in Tubular Products \& Casting Research Department, Steel Research Laboratory, JFE Steel Corp. for vigorous discussions at meetings.

Special thanks are given to Mr. Naruhito Shinbu, Mr. Toshiaki Noguchi (JFE Techno-Research Co.), Mr. Kaoru Murata (formerly Kokan Keisoku Co., one of the predecessors of JFE Tech., presently working at FEI Japan), Mr. Eiji Okunishi (formerly Kokan Keisoku Co., presently working at JEOL) for preparing TEM replica samples.

\section{REFERENCES}

1) Y. Ishiguro, T. Murayama, T. Fujita and K. Kuroda: Mater. Trans. 50 (2009) 1360-1369.

2) Y. Ishiguro, T. Murayama, T. Fujita and K. Kuroda: Mater. Trans. 50 (2009) 1370-1379.

3) Y. Ishiguro, T. Murayama, K. Sato and K. Araki: CAMP-ISIJ. 10 (1997) 703.

4) Y. Ishiguro, K. Yamada and K. Sato: CAMP-ISIJ. 10 (1997) 1466.

5) Y. Ishiguro, K. Yamada and K. Sato: Materia Japan 38 (1999) 383.

6) Y. Ishiguro, T. Murayama, K. Sato and K. Yamada: Chugoku-ShikokuBranch Joint Workshop of ISIJ No. 43 \& JIM No. 40, (2000) pp. 37.

7) Y. Ishiguro, K. Yamada and K. Sato: Materia Japan 39 (2000) 946.

8) Y. Ishiguro, K. Yamada and K. Sato: Practical Electron Microscopy and Its Application to Materials ed. by K. Maruyama, (The Iron and
Steel Institute of Japan \& The Japan Institute of Metals, Sendai, 2002) pp. 115.

9) Y. Ishiguro, T. Murayama and K. Sato: Mater. Trans. 46 (2005) 769778.

10) Y. Ishiguro, T. Murayama and K. Sato: Mater. Sci. Forum 561-565 (2007) 2029-2032.

11) Y. Ishiguro and K. Kuroda: CAMP-ISIJ. 21 (2008) 571.

12) Y. Ishiguro and K. Kuroda: AMTC Lett. 1 (2008) 128-129.

13) Y. Ishiguro and K. Kuroda: CAMP-ISIJ. 21 (2008) 1534-1537.

14) Y. Ishiguro and K. Kuroda: CAMP-ISIJ. 21 (2008) 863-866.

15) Y. Ishiguro and K. Kuroda: The 9th Asia-Pacific Microscopy Conf., (APMC-9, 2008) pp. 558-559. (Korean J. Microscopy 38 supplement (2008) 558-559)

16) Y. Ishiguro, T. Murayama, A. Chino, K. Sato, Y. Shima, A. Kido and M. Morita: Mech. Work. Steel Process. 35 (1997) 255-264.

17) Y. Ishiguro and T. Murayama: CAMP-ISIJ. 20 (2007) 436

18) Y. Ishiguro, T. Fujita and K. Kuroda: CAMP-ISIJ. 20 (2007).

19) Y. Ishiguro and K. Kuroda: CAMP-ISIJ. 21 (2008) 572.

20) Y. Ishiguro and K. Kuroda: CAMP-ISIJ. 21 (2008) 213.

21) K. Yamada and M. Niikura: CAMP-ISIJ. 6 (1993) 1710.

22) H. Murakami, S. Sanagi and T. Senuma: CAMP-ISIJ. 7 (1994) 1835.

23) K. Yamada and M. Niikura: Tetsu-to-Hagane 81 (1995) 197-202.

24) H. Murakami: Tetsu-to-Hagane 89 (2003) 544-551.

25) A. K. De, S. Vandeputte and B. C. De Cooman: Scr. Mater. 44 (2001) 695-700.

26) A. K. De, K. De Blauwe, S. Vandeputte and B. C. De Cooman: J. Alloy. Compd. 310 (2000) 405-410.

27) K. Tsunoyama, K. Sakata, T. Obara, S. Satoh, K. Hashiguchi and T. Irie: Hot- \& Cold-rolled Sheet Steels, ed. by R. Pradhan and G. Kudkovsky, (MetSoc, 1988) pp. 155-164.

28) K. Kawasaki, T. Senuma and S. Sanagi: CAMP-ISIJ. 3 (1990) 1813.

29) K. Kawasaki, T. Senuma and S. Sanagi: Int. Conf. Process. Microstruct. Prop. Microalloy Other Mod. High Strength Low Alloy Steels 1991, (1992) pp. 137-144.

30) K. Kawasaki, S. Sanagi, T. Senuma, S. Akamatsu and N. Yoshinaga: Tetsu-to-Hagane 79 (1993) 76-82.

31) Metal Databook rev.4, ed. by The Japan Institute of Metals, (Maruzen, Tokyo, Sendai, 2004) Chap. 1.2.14, pp. 20-25.

32) S. Yoshida, N. Takuchi, Y. Kawanami, M. Kajiwara and T. Mori: CAMP-ISIJ. 8 (1995) 1382.

33) Y. Kawanami, M. Kajiwara and T. Mori: CAMP-ISIJ. 8 (1995) 1383.

34) M. Kajiwara and T. Mori: CAMP-ISIJ. 10 (1997) 441.

35) J. Marian, B. D. Wirth, J. M. Perlado, G. R. Odette and T. Diaz de la Rubia: Phys. Rev. B 64 (2001) 094303.

36) F. Sasaki, Z. Tang, Y. Nagai and M. Hasegawa: The 108th Conf. Institute for Materials Research, Tohoku University, (2004), poster \#34. (http://www.imr.tohoku.ac.jp/jpn/event/kouen/pdf/2004/ posterses 10806.pdf).

37) H. Hirakawa and Y. Ishikawa: Nihon Gomu Kyoukaishi 45 (1972) 920-931.

38) M. Ashida: Nihon Gomu Kyoukaishi 57 (1984) 501-508.

39) G. E. Hammer: J. Vac. Sci. Technol. A 19 (2001) 2846-2850.

40) T. Yasunaga, T. Nakayama, K. Okumura, T. Yamauchi, T. Shimizu and M. Doi: Kobe Steel Eng. Rep. 54 (2004) 2-6.

41) T. Shimazu, K. Chikuma, T. Sakai and M. Tanino: Tetsu-to-Hagane 70 (1984) S568.

42) B. J. Lee, B. Sundman, S. I. Kim and K. G. Chin: ISIJ Int. 47 (2007) $163-171$.

43) S. Katsumata, K. Oikawa, I. Ohnuma, R. Kainuma and K. Ishida: Proc. the 13th National Symp. on Phase Diagrams, Xiamen, China (2006) pp. 167-172. 